East African Medical Journal Vol. 86 No. 12 December 2009

EXTERNAL ROOT MORPHOLOGY OF MAXILLARY FIRST PREMOLARS IN KENYAN AFRICANS

R. N. Ng'ang'a, BDS, MDS, Senior Principal Lecturer, Department of Community Oral Health, Kenya Medical Training College, P.O. Box 30195 - 00100, Nairobi, Kenya, M. A. Masiga BDS, MSc, Senior Lecturer, Department of Paediatric Dentistry and Orthodontics and S.W. Maina, BDS, MSc, Senior Lecturer, Department of Conservative and Prosthetic Dentistry, Faculty of Dental Sciences, University of Nairobi, P.O. Box 19676-00202, Nairobi, Kenya

Request for reprints to: Dr. R. N. Ng'ang'a, Department of Community Oral Health, Kenya Medical Training College, P.O. Box 30195 - 00100, Nairobi, Kenya

\title{
EXTERNAL ROOT MORPHOLOGY OF MAXILLARY FIRST PREMOLARS IN KENYAN AFRICANS
}

\author{
R. N. NG'ANG'A, M.A. MASIGA and S. W. MAINA
}

\begin{abstract}
Objective: To determine the external root morphology of the maxillary first premolars in Kenyan Africans.

Design: In vitro descriptive cross-sectional study.

Setting: School of Dental Sciences, University of Nairobi.

Subjects: One hundred and fifty five extracted maxillary first premolar teeth obtained from patients aged between 13-30 years attending dental clinics within Nairobi. Main outcome measures: Number of roots, direction of root curvature and tooth length.

Results: A total of $\mathbf{1 5 5}$ maxillary first premolars were studied, 77 from males and $\mathbf{7 8}$ from females. Overall, there were $83.2 \%$ two-rooted teeth (mean tooth length: buccal root $22.3 \mathrm{~mm}$; lingual root $21.2 \mathrm{~mm}$ ), $10.3 \%$ one-rooted (mean tooth length-22.6 mm) and $6.5 \%$ three-rooted. Three roots occurred more commonly in males than females and this was a statistically significant gender difference $(P<0.05)$. Males were found to have larger mean tooth length than females in multirooted teeth. Majority of the roots were straight $(57.2 \%)$. Distal and " $S$ " curvatures were the commonest $(19.1 \%$ and $10.2 \%$ respectively). There were no significant gender differences in direction of root curvature $(\mathrm{P}>0.05)$.

Conclusions: Maxillary first premolars were mostly two-rooted with straight roots. Males presented with two or three roots more often than females and had significantly larger mean tooth lengths.
\end{abstract}

\section{INTRODUCTION}

Adequate knowledge of dental morphology is necessary before instituting dental therapy and for accurate interpretation of pre-operative radiographs (1).

An understanding of external morphology is important in various treatment modalities such as surgical endodontics, periodontal surgery, dental extractions and orthodontic tooth movement $(2,3)$.

Genetic determination of dental morphology and the anthropological associations of certain dental characteristics with certain racial groups have been reported (4-6). The literature reveals scanty information on the tooth morphology of Kenyans of African descent.

Previous studies have reported maxillary first premolar to be either single or multi- rooted. The occurrence of one root has been reported to range from $20 \%$ to $56 \%$, two- roots $42 \%$ to $70 \%$ and three roots $0.0 \%$ to $10 \%$ (6-12). One Japanese study (13) found males $(25.5 \%)$ presenting with two roots more often than females $(17.6 \%)$.

There is paucity of information on direction of root curvature. The roots of this tooth have been found to be either straight or curved in variable directions: lingually, buccally, mesially, distally, or to have an " $S$ " curve. A study by Ingle et al. (14) found most of the roots of the maxillary first premolars to be straight while Percora et al. (11) reported most of the roots to curve distally.

The length of the maxillary first premolar has been reported to range between $15.5 \mathrm{~mm}-28.9 \mathrm{~mm}$ $(11,15-17)$. The aim of the study was to determine the external morphology of maxillary first premolars in Kenyan males and females of African descent with regard to the number of roots, direction of root curvature and tooth length. 


\section{MATERIALS AND METHODS}

This was an in-vitro study where freshly extracted maxillary first premolar teeth were collected from Kenyan Africans aged between 13-30 years. These patients were drawn from the main dental hospitals in Nairobi, the capital city of Kenya. These hospitals were Kenyatta National Hospital, the countries referral hospital, Social Service League Dental Hospital and University of Nairobi Dental Hospital.

Approval for the study was obtained from the $\mathrm{KNH}$ Ethical Research Committee (KNH - ERC) and all patients gave informed consent.

Exclusion criteria: The following teeth were excluded from the study:

(i) Teeth from non-Kenyan Africans and of nonAfrican Kenyans.

(ii) Teeth with developmental abnormalities of the crowns and roots.

(iii) Teeth with cusp tips that were grossly carious restored or had undergone attrition.

(iv) Teeth, whose roots were not fully formed, fractured or had extensive cementum deposition around the apex.

(v) Contra-lateral (antimere) premolar tooth.

The sample contained many maxillary first premolars from orthodontic extractions. Immediately after extraction, the premolar teeth were stored for 30 minutes in $5.25 \%$ sodium hypochlorite solution in two plastic containers as per gender. The specimens were then examined with the help of a magnifying glass (x 2.5 magnification). Those satisfying the inclusion criteria were selected and preserved in $10 \%$ formalin.

The number of roots was determined by direct visual observation of each premolar tooth (6). A tooth was categorised as:

(i) One-rooted when one external root was observed.

(ii) Two-rooted distinct when two distinct external roots were observed.

(iii) Two-rooted fused when externally two roots were joined almost to the root apices. This was further confirmed by making an access cavity and examining the floor of the pulp chamber by direct visual observation with the help of the dental chair light and a dental probe. The tooth revealed the presence of at least two canal orifices on the floor of the pulp chamber.

(iv) Three-rooted when three external roots were observed. Figure 1 (a-d) shows the four root types.

Figure 1 (a-d)

Premolars depicting one root (a), two distinct roots (b), two fused roots (c), and three roots (d)

(a)

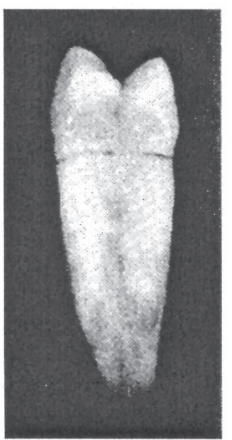

(c)

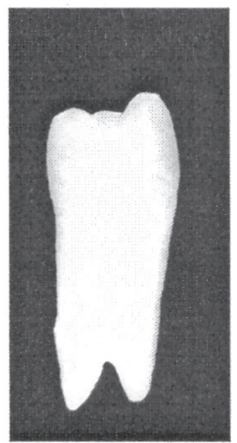

(b)

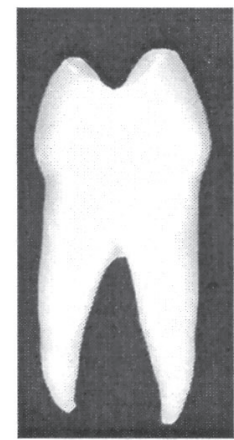

(d)

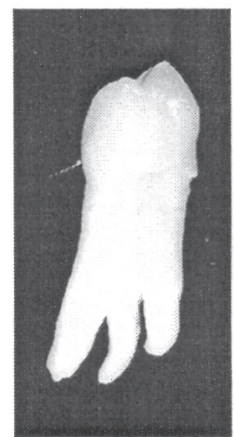

The direction of root curvature was determined by visual examination of the tooth from the buccal, lingual, mesial and distal aspects and also by aligning a reamer perpendicular to the long axis of the premolar from the cusp tip towards the root apex [Figure 2(a-c)]. Individual roots were recorded as straight, curving towards the mesial, distal, buccal, and lingual or having an "S" curvature.

\section{Figure 2 (a-c)}

Premolars showing straight alignment of a reamer with cusp tip and root apex in a straight root (a), deviation (curvature) of root apex in relation to a reamer aligned perpendicular to the long axis of the tooth from the cusp tip in a one-rooted premolar (b), and a two-rooted premolar (c)

(a)

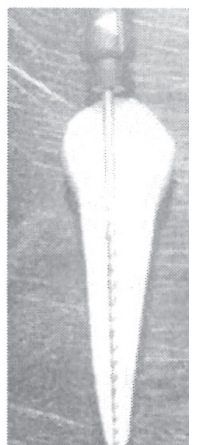

(b)

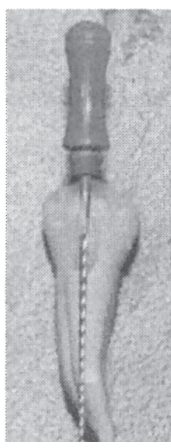


(c)

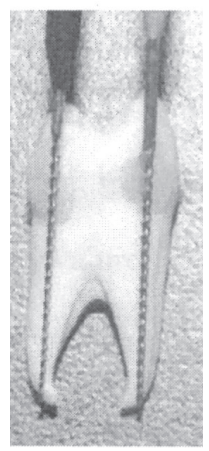

The premolar tooth length was measured to the nearest 0.1 millimeters $(\mathrm{mm})$ using a Boley gauge. The measurements were done from the buccal or lingual (palatal) cusp tip to the corresponding root apex (Figure 3).

Figure $3(\mathbf{a}, \mathbf{b})$

Diagrams showing the measuring reference points used to determine tooth length from the cusp tip to the root apex for a single-rooted premolar (a), and a two-rooted premolar (b) (a)

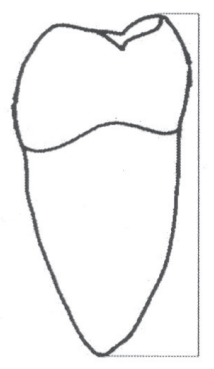

(b)

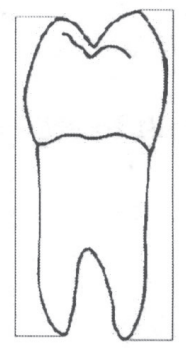

Data analysis: Data was analysed using descriptive statistics to determine mean tooth length, lowest and highest measurements, standard deviations to show variability in tooth length, and frequencies in number of roots and direction of root curvature. Independent $\mathrm{t}$ - test was used to assess gender differences in tooth length. Pearson Chi-square test was used to assess gender differences in number of roots and direction of root curvature. In situations where assumptions of Chi-square tests were not met, Fisher's exact test was employed to assess gender differences in number of roots and direction of root curvature.

\section{RESULTS}

One hundred and fifty five maxillary first premolars were examined, 77 from males and 78 from females. Data reliability was achieved by assessing the intraexaminer reliability where the following Kappa's were obtained; 0.93 in the identification of number of roots and 0.91 for identification of direction of root curvature. A paired $t$-test $(t=1.18$; $p>0.05$ ) was used to assess the reliability of tooth length measurements ( $p>0.05$ show no statistical significant difference).

In the combined data for both males and females, $83.2 \%$ of the roots were two rooted (distinct plus fused), $10.3 \%$ of the teeth were one-rooted and $6.5 \%$ three-rooted (Table 1 and Figure 4).

In both genders, two-rooted premolars were the most common. Males $(11.7 \%)$ presented with three roots more often than females $(1.3 \%)$ and this was statistically significant $\left(X^{2}=11.79 ; 2 \mathrm{df} ; \mathrm{P}<0.05\right.$ $[\mathrm{p}=0.02])$.

In single rooted maxillary first premolars, $81.3 \%$ had straight roots, $12.5 \%$ distal curvature, and $6.3 \%$ had an "S" curvature. In two rooted teeth, the buccal (56.6\%) and lingual (55.8\%) roots were mostly straight (Table 2). Gender differences in direction of root curvature (straight versus all other curvatures combined $)$ were not statistically significant $\left(X^{2}=1.05\right.$; $1 d f ; p>0.05$ [0.636]).

Table 1

Percentage number of roots in maxillary first premolars ( $n=155$ teeth)

\begin{tabular}{lcccccc}
\hline Gender & $\begin{array}{c}\text { Number of } \\
\text { teeth }\end{array}$ & $\begin{array}{c}\text { One-rooted } \\
(\%)\end{array}$ & $\begin{array}{c}\text { Two-rooted distinct } \\
(\%)\end{array}$ & $\begin{array}{c}\text { Two-rooted fused } \\
(\%)\end{array}$ & $\begin{array}{c}\text { Three-rooted } \\
(\%)\end{array}$ \\
& No. $\quad(\%)$ & & & & 11.7 \\
\hline Males & 77 & 100 & 3.9 & 72.7 & 32.1 & 1.3 \\
\hline Females & 78 & 100 & 16.6 & 50.0 & 21.9 & 6.5 \\
\hline Total & 155 & 100 & 10.3 & 61.3 & 5 \\
\hline
\end{tabular}


Figure 4

Percentage number of roots in maxillary first premolars ( $n=155$ teeth)

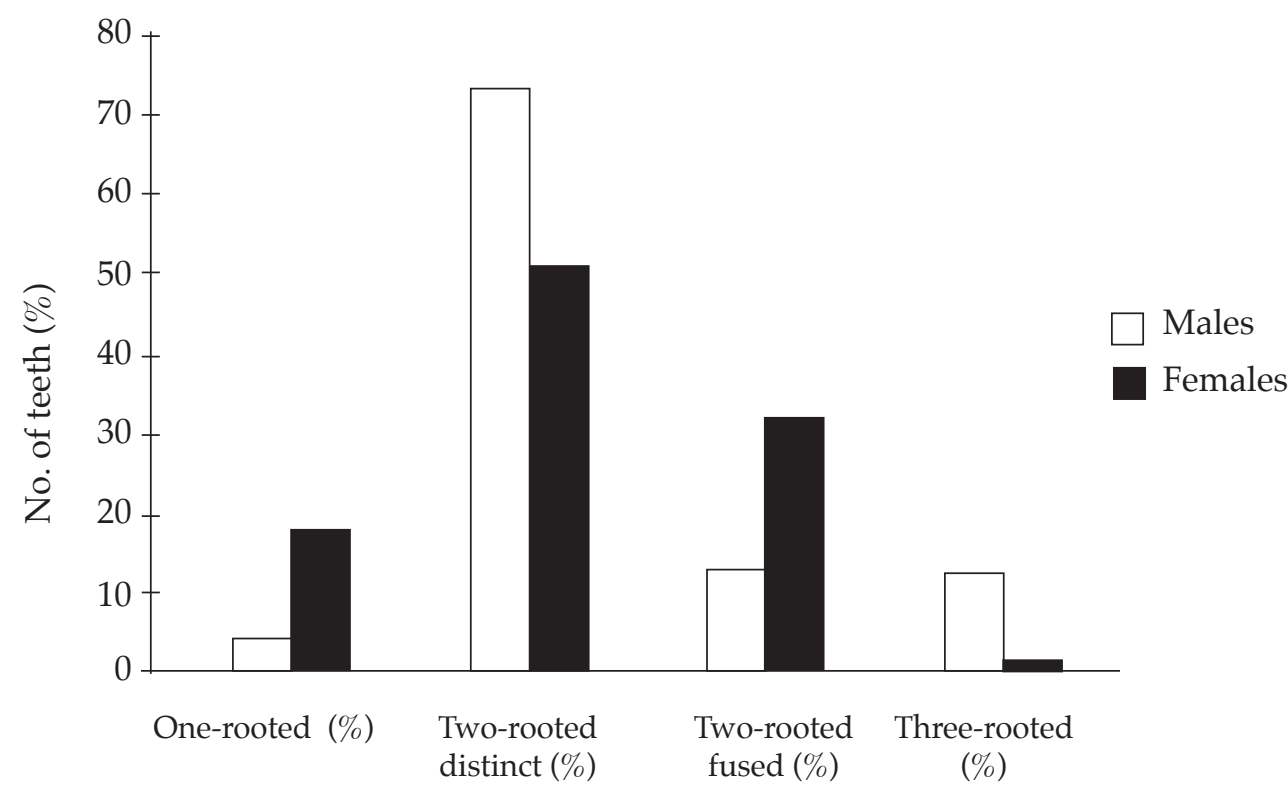

Table 2

Distribution of number of roots and their curvatures in maxillary first premolars in Kenyan males $(M)$ and females $(F)$

\begin{tabular}{|c|c|c|c|c|c|c|c|c|c|c|c|c|c|c|}
\hline & \multirow{2}{*}{\multicolumn{2}{|c|}{ Straight }} & \multirow{2}{*}{\multicolumn{2}{|c|}{ Lingual }} & \multirow{2}{*}{\multicolumn{2}{|c|}{ Buccal }} & \multirow{2}{*}{\multicolumn{2}{|c|}{ Mesial }} & \multicolumn{5}{|c|}{ Direction of root curvature. } & \multirow{2}{*}{$\begin{array}{l}\text { Total } \\
\text { roots } \\
\text { per } \\
\text { vature }\end{array}$} \\
\hline & & & & & & & & & \multicolumn{2}{|c|}{ Distal } & \multicolumn{2}{|c|}{ “S”-curve } & \multirow{2}{*}{$\begin{array}{l}\text { cur } \\
\text { No. }\end{array}$} & \\
\hline & No. & $(\%)$ & No. & $(\%)$ & No. & $(\%)$ & No. & $(\%)$ & No. & $(\%)$ & No. & $(\%)$ & & $(\%)$ \\
\hline \multicolumn{15}{|c|}{ One-rooted } \\
\hline Male & 2 & 66.6 & 0 & 0.0 & 0 & 0.0 & 0 & 0.0 & 1 & 33.3 & 0 & 0.0 & 3 & 100 \\
\hline Female & 11 & 84.6 & 0 & 0.0 & 0 & 0.0 & 0 & 0.0 & 1 & 7.7 & 1 & 7.7 & 13 & 100 \\
\hline Total & 13 & 81.3 & 0 & 0.0 & 0 & 0.0 & 0 & 0.0 & 2 & 12.5 & 1 & 6.3 & 16 & 100 \\
\hline \multicolumn{15}{|c|}{ Two-rooted } \\
\hline Male & 38 & 58.5 & 5 & 7.7 & 1 & 1.5 & 1 & 1.5 & 18 & 27.7 & 2 & 3.0 & 65 & 100 \\
\hline B Female & 35 & 54.7 & 4 & 6.3 & 2 & 3.1 & 2 & 3.1 & 11 & 17.2 & 10 & 15.6 & 64 & 100 \\
\hline Total & 73 & 56.6 & 9 & 7.0 & -3 & 2.3 & 3 & 2.3 & 29 & 22.5 & 12 & 9.3 & 129 & 100 \\
\hline L Male & 40 & 61.5 & 1 & 1.5 & 5 & 7.7 & 2 & 3.1 & 12 & 18.5 & 5 & 7.7 & 65 & 100 \\
\hline Female & 32 & 50.0 & 1 & 1.6 & 11 & 17.2 & 2 & 3.1 & 9 & 14.1 & 9 & 14.1 & 64 & 100 \\
\hline Total & 72 & 55.8 & 2 & 1.6 & 16 & 12.4 & 4 & 3.1 & 21 & 16.3 & 14 & 10.9 & 129 & 100 \\
\hline \multicolumn{15}{|c|}{ Three-rooted } \\
\hline Male & 6 & 60.0 & 0 & 0.0 & 0 & 0.0 & 0 & 0.0 & 2 & 20.0 & 1 & 10.0 & 9 & 100 \\
\hline Female & 0 & 0.0 & 1 & 10.0 & 0 & 0.0 & 0 & 0.0 & 0 & 0.0 & 0 & 0.0 & 1 & 100 \\
\hline MB Total & 6 & 60.0 & 1 & 10.0 & 0 & 0.0 & 0 & 0.0 & 2 & 20.0 & 1 & 10.0 & 10 & 100 \\
\hline Male & 6 & 66.7 & 0 & 0.0 & 0 & 0.0 & 0 & 0.0 & 2 & 22.2 & 1 & 11.1 & 9 & 100 \\
\hline Female & 0 & 0.0 & 1 & 100 & 0 & 0.0 & 0 & 0.0 & 0 & 0.0 & 0 & 0.0 & 1 & 100 \\
\hline DB Total & 6 & 60.0 & 1 & 10.0 & 0 & 0.0 & 0 & 0.0 & 1 & 10.0 & 2 & 20.0 & 10 & 100 \\
\hline Male & 4 & 44.4 & 0 & 0.0 & 0 & 0.0 & 1 & 11.1 & 2 & 22.2 & 2 & 22.2 & 9 & 100 \\
\hline Female & 0 & 0.0 & 0 & 0.0 & 1 & 100 & 0 & 0.0 & 0 & 0.0 & 0 & 0.0 & 1 & 100 \\
\hline L Total & 4 & 44.4 & 0 & 0.0 & 1 & 10.0 & 1 & 10.0 & 2 & 20.0 & 2 & 20.0 & 10 & 100 \\
\hline $\begin{array}{l}\text { Total roots } \\
\text { per curvatu } \\
\text { (No. and \% }\end{array}$ & $\begin{array}{l}174 \\
\text { ure } \\
\text { o). }\end{array}$ & 57.2 & 13 & 4.3 & 20 & $6.6 \%$ & 8 & 2.6 & 58 & 19.1 & 31 & 10.2 & 304 & 100 \\
\hline
\end{tabular}


Table 3

Maxillary first premolars tooth length $(\mathrm{mm})$ by gender

\begin{tabular}{|c|c|c|c|c|c|c|c|c|}
\hline $\begin{array}{l}\text { Category } \\
\text { of } \\
\text { premolar }\end{array}$ & Gender & $\begin{array}{l}\text { No. of } \\
\text { teeth }\end{array}$ & $\begin{array}{l}\text { Minimum } \\
\text { length }\end{array}$ & $\begin{array}{l}\text { Maximum } \\
\text { length }\end{array}$ & $\begin{array}{c}\text { Std } \\
\text { deviation }\end{array}$ & $\begin{array}{l}\text { Mean } \\
\text { tooth } \\
\text { length }\end{array}$ & $\begin{array}{c}\text { T-value } \\
\text { (Independent } \\
\text { t-test) }\end{array}$ & P-value \\
\hline \multirow[t]{3}{*}{ One-rooted } & Male & 3 & 22.0 & 23.5 & 0.76 & 22.8 & & \\
\hline & Female & 13 & 20.0 & 25.2 & 1.63 & 22.6 & 0.43 & $0.680^{* *}$ \\
\hline & $\begin{array}{l}\text { Combined } \\
(\mathrm{M}+\mathrm{F})\end{array}$ & 16 & 20.0 & 25.2 & 1.48 & 22.6 & & \\
\hline \multicolumn{9}{|l|}{ Two-rooted } \\
\hline & Male & 65 & 20.0 & 27.2 & 1.51 & 22.8 & & \\
\hline & Female & 64 & 19.0 & 24.8 & 1.31 & 21.7 & 4.217 & $0.003^{*}$ \\
\hline \multirow[t]{3}{*}{ B } & Combined & 129 & 19.0 & 27.2 & 1.50 & 22.3 & & \\
\hline & Male & 65 & 18.5 & 25.0 & 1.45 & 21.6 & & \\
\hline & Female & 64 & 18.0 & 23.2 & 1.33 & 20.9 & 2.809 & 0.031 * \\
\hline $\mathrm{L}$ & Combined & 129 & 18.0 & 25.0 & 1.49 & 21.2 & & \\
\hline \multicolumn{9}{|c|}{ Three-rooted } \\
\hline $\mathrm{MB}$ & Male & 9 & 22.2 & 25.0 & 0.889 & 23.3 & & \\
\hline DB & Male & 9 & 22.2 & 24.3 & 0.890 & 22.8 & & \\
\hline $\mathrm{L}$ & Male & 9 & 21.0 & 25.0 & 1.324 & 23.1 & & \\
\hline $\mathrm{MB}$ & Female & 1 & - & - & - & 23.4 & & \\
\hline DB & Female & 1 & - & - & - & 23.4 & & \\
\hline $\mathrm{L}$ & Female & 1 & - & - & & 23.2 & & \\
\hline
\end{tabular}

Combined $=\mathrm{M}+\mathrm{F}^{* *}=$ not significant ${ }^{*}=$ significant difference

$\mathrm{B}=$ buccal $\mathrm{L}=$ lingual $\mathrm{MB}=$ mesio-buccal $\mathrm{DB}=$ disto-buccal

In the one-rooted maxillary first premolars the difference in the mean tooth length for males (22.8 $\mathrm{mm})$ and females $(22.6 \mathrm{~mm})$ was not statistically significant $(\mathrm{P}>0.05)$. In the two-rooted premolar, both the mean buccal and mean lingual tooth lengths were significantly larger in males than in females $(\mathrm{P}<0.05)$. Details of the findings on tooth length for the maxillary first premolar are presented in Table 3.

\section{DISCUSSION}

Results from studies carried out in different populations on number of roots in maxillary first premolars have reported various racial variations (6-12). The present study showed that $83.2 \%$ of these teeth in males and females (combined) had two roots, $10.3 \%$ one root and $6.5 \%$ three-roots. In two rooted teeth, females had more of the fused-root form while males had more of the distinct-root form (Table 1 and Figure 4). Two and three-rooted teeth were significantly more common in males than in females, a finding which was similar to a previous study among the Japanese (13).

Loh (6) studied maxillary first premolar root morphology in a Singaporean population and, similar to the present study, differentiated between two-rooted distinct and two-rooted fused roots. The author reported that $50.6 \%$ of the teeth in the sample were two-rooted $(63.4 \%$ fused roots and $36.6 \%$ distinct roots), while in the Kenyans, $83.2 \%$ of the teeth were two-rooted $(73.7 \%$ had distinct roots and $26.3 \%$ fused roots). Since both studies used similar method in the identification of number of roots, the differences may be attributed to racial differences.

The tooth is often encountered with a straight root (14), which is in agreement with the present study. However, other studies have reported the distal curvature to be the most frequent (11). These differences are probably related to methodological and racial factors. In the interpretation of the results for root curvature, it is worthwhile noting that there may have been an under-representation of curved roots in the present sample since fractured roots (which occur more frequently in curved roots) (2), were excluded from the study. There were no statistically significant gender differences in root curvature, although the statistical analysis for gender differences in root curvature was done between "straight" versus all other curvatures combined.

Detection of direction of root curvature from radiographs is not always straightforward. This is 
particularly so in multirooted teeth and when the curvatures are buccal or lingual(1). Knowledge of the external morphology of roots is therefore necessary in order to help the clinician interpret curvature more accurately.

The combined (males + females) tooth length results were found to lie within the range reported by other authors (11,15-17). The combined data on the two-rooted premolar shows the buccal mean tooth length $(22.3 \mathrm{~mm})$ to be larger than the lingual mean tooth length $(21.2 \mathrm{~mm})$. An earlier study donein Kenya by Maina and Wagaiyu (15) reported the mean lingual tooth length $(22.4 \mathrm{~mm})$ to be larger than the buccal $(21.8 \mathrm{~mm})$. This was in contrast to the present study and previous studies $(11,16,17)$ that have reported the buccal root to be longer than the lingual root. These differences may be due to the measuring reference points, in the present study being the root apex to the corresponding cusp tip. Maina and Wagaiyu (15) used the buccal cusp for both buccal and lingual measurements, which may account for the findings of a longer lingual root than buccal root. Similar to other studies (18), males had statistically significant larger mean tooth length than females $(P<0.05)$.

Although radiographs are relied on in the determination of correct working length, some authors have expressed the view that radiographs exaggerate the working length due to distortion. An extracted tooth is on average $1.2 \mathrm{~mm}$ shorter than the tooth image in a diagnostic radiograph (19). Stock and Nehammer (20) have stressed the importance of prior knowledge of average tooth lengths and root anatomy for successful endodontic treatment. Knowing the mean tooth length of a particular tooth type in a specific population and gender will guide the operator in the determination of a more accurate working length and hence correct instrumentation. However, it is equally important for a clinician to appreciate the wide range in tooth length that one is likely to encounter. From an orthodontic point of view, the number of roots, the presence of root curvature and the size of the tooth being moved are important in terms of the forces being applied and the anchorage requirements. Higher forces would be necessary to move longer roots, multiple roots, which also offer better anchorage than short roots (3).

In conclusion, the external root morphology of maxillary first premolars from Kenyan males and females was found to be mostly two-rooted. Threerooted teeth are more likely to be found in Kenyan males than females. The mean tooth length in single-rooted maxillary first premolar showed no statistically significant gender differences. However, in two-rooted maxillary first premolars, males had statistically significant larger mean tooth length than females. Majority of the teeth in both genders had straight roots. Where there was curvature of roots, distal and " $\mathrm{S}$ " -curvatures were relatively common while mesial, buccal and lingual curvatures were rare.

\section{REFERENCES}

1. Fishel, D. and Tamse, A. Dentists' mistakes in making correct radiographic diagnosis. Quit Int. 1978; 6: 59-64.

2. Laskin, D.M. Extraction of teeth (Exodontia): Oral and Maxillofacial Surgery. $1^{\text {st }}$ ed. St. Louis Missouri, Mosby company U.S.A., 1989; pp: 2-22.

3. Seiders, G.W. Orthodontic principles. Dent. Clin. North Am. 1972; 16: 459-466.

4. Dahlberg, A.A. Geographic distribution and origin of dentitions. Int. Dent. J. 1965; 15: 348-355.

5. Bailit, H.L. Dental variation among populations: An anthropologic view. Dent. Clin. North. Am. 1975; 19:125-139.

6. Loh, H.S. Root morphology of maxillary first premolar in Singaporeans. Aust. Dent. J. 1998; 43: 399-402.

7. Mueller, A.H. Anatomy of the root canals. J. Am. Dent. Assoc. 1933; 20:1361- 1386

8. Carns, E.J. and Skidmore, A.E. Configurations and deviations of root canals of maxillary first premolars. Oral Surg. 1973; 36: 880-886.

9. Kerekes, K. and Tronstad, L. Morphometric observations on root canals of human premolars. J. Endod. 1977; 3:74-79.

10. Vertucci, F.J. and Gegauff, A. Root canal morphology of the maxillary first premolars. J. Am. Dent. Assoc. 1979; 99:194-198.

11. Pecora, J.D., Saquay, M.D., Sousa-Neto, M.D. and Woelfel, J.B. Root form and canal anatomy of maxillary first premolars. Braz. Dent. J. 1991; 2: 87-94.

12. Chaparro, A.J., Segura, J.J., Guerrero, E., et al Number of root canals in maxillary first premolars: Study of an Andalusian population. Endod. Dent. Traumatol. 1999; 15: 65-67.

13. Aoki, K. Morphological studies on the roots of maxillary premolars in Japanese. Shikwa Gakuho. 1990; 90: 181-199.

14. Ingle, J. I., Beveridge, E. E., Luebke, R. G. and Brooks, E.V. Endodontics. Coronal endodontic cavity preparations. 2nd ed. Philadelphia: Lea and Febiger 1976; pp: 106-213.

15. Maina, S.W. and Wagaiyu, C.K. The average tooth length in a black Kenyan population. East Afr. Med. J. 1990; 67:333-338.

16. Okpo, H.E.A. and Akpata, E.S. Tooth length in Nigerians. Int. Endod. J. 1986; 19: 248- 252.

17. Bjorndal, A.M.,Henderson, W.G., Skidmore, A.E. and Kellner, F.H. Anatomic measurements of human teeth extracted from males between ages 17 and 21 years. Oral Surg. 1974; 38:791-803.

18. Lavelle, C.L.B. Maxillary and mandibular tooth size in different racial groups and in different occlusal categories. Am. J. Orthod. 1972; 61:29-37.

19. Vande Vorde, H.E. and Bjorndal, A.M. Estimating endodontic working length with paralleling radiographs. Oral Surg. 1969; 27:106-110.

20. Stock, C.J.R. and Nehammer, C.F. Endodontics in practice. 2nd ed. Great Britain: Latimer Tend and Company, 1990; p: 6. 